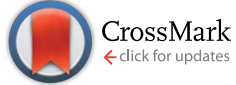

Cite this: RSC Adv., 2015, 5, 34047
Received 10th November 2014 Accepted 7th April 2015

DOI: 10.1039/c4ra14216k

www.rsc.org/advances

\section{Biodesulphurization of fossil fuels: energy, emissions and cost analysis}

\begin{abstract}
L. Alves, ${ }^{\star a}$ S. M. Paixão, ${ }^{\star a}$ R. Pacheco, ${ }^{b}$ A. F. Ferreira ${ }^{b}$ and C. M. Silva*b
In order to achieve stringent environmental and safety requirements, refineries are in search of "green" and cost-effective methods for crude oil desulphurization. Combined desulphurization technologies are being studied, including bioprocessing to upgrade fossil fuels. Using biodesulphurization (BDS), which is a biochemical process mediated by specific microorganisms, it is possible to desulphurize most of the hydrodesulphurization (HDS) recalcitrant sulphur compounds under mild operating conditions, making it a simple and eco-friendly process. In this study, two BDS process designs are compared, in terms of energy consumption, greenhouse gas emissions and operational costs by following a life cycle assessment (LCA) and life cycle cost (LCC) based methodology. The industrial HDS process is used as the reference technology for sulphur removal from fossil fuels. Different theoretical scenarios were considered and the best BDS results are scaled-up to evaluate a case study of providing ultra low sulphur diesel to an urban taxi fleet. This study exploits the potential of BDS as a cost-effective and ecofriendly alternative or complementary technology to the commonly HDS towards ultra low sulphur fuels.
\end{abstract}

\section{Introduction}

The combustion of fossil fuel generates emissions of sulphur as sulphur dioxide $\left(\mathrm{SO}_{2}\right)$, that is corrosive and toxic, and as fine particulate matter of metal sulphates. These emissions are responsible for damage in many different areas. Gaseous chemical compounds of sulphur constitute a major health hazard when present in the air: the large-ring thiophenes, such as dibenzothiophene, abundant in crude oil, are toxic to mammals; ${ }^{1} \mathrm{SO}_{2}$ gas at high levels can cause bronchial irritation and trigger asthma attacks in susceptible individuals and longterm exposure to combustion-related fine particulate air pollution is an important risk factor for cardio-pulmonary and lung cancer mortality. ${ }^{2,3}$ In addition, incomplete burning of liquid fossil fuels causes emissions of aromatic sulphur compounds to the air, ${ }^{4}$ and the oxidation of sulphur compounds in the atmosphere eventually leads to aerosol of sulphuric acid. This aerosol causes acid rains, which are responsible for the corrosion of many infrastructures and monuments, and even affect several living organisms including agricultural crops, thus causing direct damage to the economy. ${ }^{5}$ The aerosol is also harmful to the stratospheric ozone contributing to the hole on the Earth's protective ozone layer. ${ }^{6}$ Lastly, sulphur compounds even prevent functioning of all major pollution control

${ }^{a}$ LNEG - Laboratório Nacional de Energia e Geologia, IP, Unidade de Bioenergia, Estrada do Paço do Lumiar, 22, 1649-038 Lisboa, Portugal. E-mail: luis.alves@lneg. pt; susana.alves@lneg.pt

${ }^{b} I D M E C$, Instituto Superior Técnico, Universidade de Lisboa, Av. Rovisco Pais, 1, 1049o01 Lisboa, Portugal.E-mail: carla.silva@tecnico.ulisboa.pt technologies such as automobile catalytic converters ${ }^{7}$ making it more difficult to fight against pollution.

Since gasoline, diesel and non-transportation fuels account for 75 to $80 \%$ of the total refinery products, ${ }^{8}$ it is only natural that countries find the reductions of sulphur concentration in fuels as the most effective way to decrease the amount of $\mathrm{SO}_{2}$ emitted in to the air and limit its prejudicial effects. ${ }^{9}$ Therefore, as a response to the environmental and health problems, there has been an increasing concern regarding the sulphur levels in fossil fuels and its derivatives. Throughout the world countries have been drastically reducing the legal limits on sulphur concentration of these energy sources. For the transportation fuels, namely gasoline and diesel, a 500 ppm limit was admissible in the 90's, but this limit decayed to $10 \mathrm{ppm}$ for EU, since 2009, and $15 \mathrm{ppm}$ for US, since 2006. ${ }^{10}$ Furthermore, it has to be expected that the sulphur level in on-road and off-road gasoline and diesel requirements will become stricter in the foreseeable future towards ultra low sulphur fuels, approaching zero sulphur emissions from burned fuels. Therefore, the efficiency of the desulfurization technologies becomes a key point..$^{\mathbf{8 1 1}}$

Sulphur is the third most common element in crude oil composition after carbon and hydrogen, but the total sulphur content of crude oil varies from reservoir to reservoir, with an average content of 0.03 to $7.89 \%$ by weight. ${ }^{12}$ Depending on the amount of sulphur the crude oil can be sweet or sour. When the total sulphur level in the oil is less than $0.5 \%$ the oil is called sweet and if it is more than that the oil is called sour. ${ }^{13}$ The sulphur compounds can be found in two forms: inorganic and organic, but the organosulphur compounds such as thiols, 